\title{
Child consumption of fruit and vegetables: the roles of child cognitions and parental feeding practices
}

\author{
Elisabeth L Melbye ${ }^{1, *}$, Nina C $\varnothing$ verby $^{2}$ and Torvald $\varnothing$ gaard $^{1}$ \\ ${ }^{1}$ Norwegian School of Hotel Management, University of Stavanger, 4036 Stavanger, Norway: ${ }^{2}$ Department of \\ Public Health, Sport and Nutrition, University of Agder, Kristiansand, Norway
}

Submitted 28 February 2011: Accepted 9 September 2011: First published online 170 0ctober 2011

\begin{abstract}
Objective: To examine the roles of child cognitions and parental feeding practices in explaining child intentions and behaviour regarding fruit and vegetable consumption.

Design: Cross-sectional surveys among pre-adolescent children and their parents. Setting: The child questionnaire included measures of fruit and vegetable consumption and cognitions regarding fruit and vegetable consumption as postulated by the Attitude-Social Influence-Self-Efficacy (ASE) model. The parent questionnaire included measures of parental feeding practices derived from the Comprehensive Feeding Practices Questionnaire (CFPQ).

Subjects: In total, 963 parents and 796 students in grades 5 and 6 from eighteen schools in the south-western part of Norway participated.

Results: A large portion of child intention to eat fruit and child fruit consumption was explained by child cognitions ( $29 \%$ and $25 \%$, respectively). This also applied to child intention to eat vegetables and child vegetable consumption ( $42 \%$ and $27 \%$, respectively). Parent-reported feeding practices added another $3 \%$ to the variance explained for child intention to eat fruit and $4 \%$ to the variance explained for child vegetable consumption.

Conclusions: The results from the present study supported the application of the ASE model for explaining the variance in child intentions to eat fruit and vegetables and in child consumption of fruit and vegetables. Furthermore, our findings indicated that some parental feeding practices do have an influence on child intentions and behaviour regarding fruit and vegetable consumption. However, the role of parental feeding practices, and the pathways between feeding practices and child eating intentions and behaviour, needs to be further investigated.
\end{abstract}

\author{
Keywords \\ Fruit and vegetables \\ Child cognitions \\ Parental feeding practices
}

Norwegian dietary surveys from 2000 showed that the average intake of fruit and vegetables (F\&V) among children and adolescents was less than half the recommended amount ${ }^{(1)}$. Subsequent cross-national surveys among children and adolescents also found that the F\&V intake was far from reaching population goals and foodbased dietary guidelines in all the surveyed countries ${ }^{(2)}$. The promotion of healthy eating (including daily $\mathrm{F} \& \mathrm{~V}$ consumption) in pre-adolescent children is important, since food habits established in childhood may to a certain extent track into adolescence and adulthood ${ }^{(3-5)}$. Furthermore, food habits in pre-adolescent children may be more flexible to change than food habits in adolescents and adults ${ }^{(3)}$. According to Hanson et al. ${ }^{(6)}$, at age 11 years, parents are considered to be the most important social agent impacting upon diet. In line with this, De Bourdeaudhuij et al. ${ }^{(7)}$ indicated that parental influence is important for daily $\mathrm{F} \& \mathrm{~V}$ consumption in 11-year-old children. We believe that increased knowledge about the relationships between parental influence and eating behaviour in pre-adolescent children is needed to develop successful interventions for this group of the population.

Parents influence their children's eating behaviour in many different ways, especially through their feeding practices ${ }^{(8)}$. Most previous studies assessing parental feeding practices as determinants of children's eating behaviour have included just a few feeding practices, such as restrictive feeding and pressure to eat. These practices are aspects of control over child food intake, and are typically measured with the Child Feeding Questionnaire $(\mathrm{CFQ})^{(9)}$. Although controlling feeding practices seem to be widely used by parents in an attempt to secure a well-balanced diet for their children ${ }^{(10)}$, some studies have proved counterproductive effects of these practices, as parents who exert too much control over child food intake tend to have children with an increased 


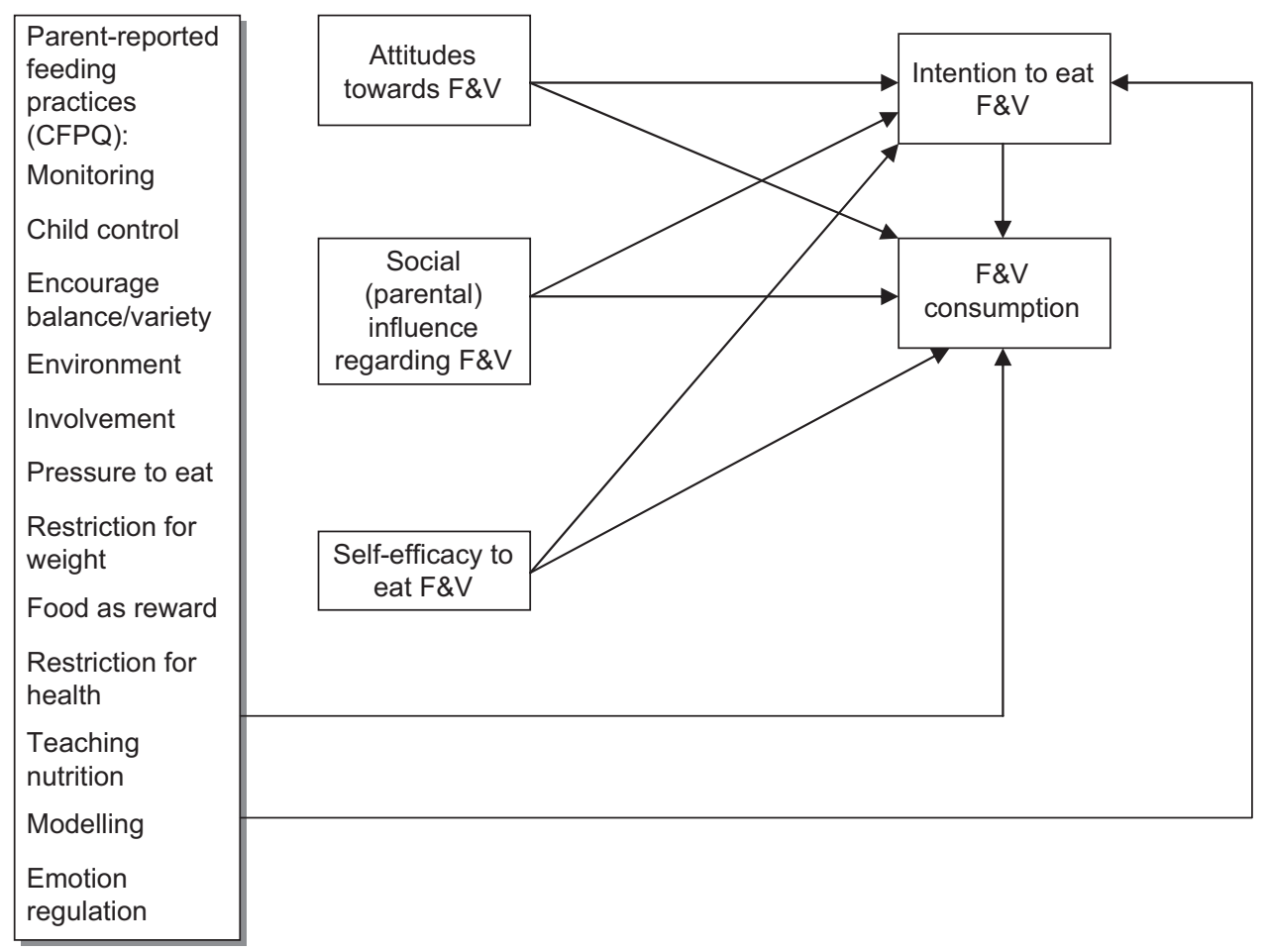

Fig. 1 Expansion of the Attitude-Social Influence-Self-Efficacy (ASE) model on child intention to eat fruit and vegetables (F\&V) and child F\&V consumption by inclusion of parent-reported feeding practices measured by the Comprehensive Feeding Practices Questionnaire (CFPQ)

preference for high-fat foods and higher levels of snackfood intake ${ }^{(11)}$. The emphasis on parental control in previous feeding practices measures has lately been accompanied by increased research on other important practices. Parental modelling of healthy eating and exposure to healthy foods are examples of other feeding practices that may be effective ${ }^{(12-15)}$.

Traditionally, the Theory of Planned Behaviour $(\mathrm{TPB})^{(16)}$, the Attitude-Social Influence-Self-Efficacy (ASE) model $^{(17)}$ and similar cognitive theories derived from social psychology are seen as comprehensive models for explaining and predicting health behaviour, including eating behaviour. In the TPB and the ASE model, attitude, subjective norm (social influence) and perceived behavioural control (self-efficacy) are the central cognitive factors. These factors are believed to influence behavioural intention, which is assumed to be the primary determinant of behaviour. More distal variables, such as the social and physical environment, are theorized to influence health behaviour through the variables of these models ${ }^{(16)}$. However, some studies suggest that cognitive models such as these are unable to fully account for the more distal variables ${ }^{(18-20)}$. Moreover, some distal variables are hypothesized to have a direct effect on health behaviour, thus bypassing the proximal cognitive factors ${ }^{(21)}$.

In the present study we built upon the conceptual framework of Hewitt and Stephens ${ }^{(22)}$ and constructed a model based on variables from the ASE model and the
Comprehensive Feeding Practices Questionnaire (CFPQ) ${ }^{(23)}$ to examine the roles of child cognitions and parental feeding practices in explaining child intention to eat $F \& V$ and child self-reported F\&V consumption. More specifically, we aimed to test if the inclusion of multiple parental feeding practices (not only controlling and restrictive practices) could increase the explanatory power of the ASE model, and to assess the importance of each variable in explaining the variance in child intention to eat $\mathrm{F} \& \mathrm{~V}$ and in child self-reported consumption of F\&V. The relationships under study are presented in Fig. 1.

\section{Methods}

\section{Procedures and participants}

Participants were recruited through primary schools in two neighbouring municipalities (Gjesdal and Sandnes) in the south-western part of Norway. All primary schools in these municipalities were asked to participate in the study, and eighteen out of twenty-five schools (72\%) agreed. In total, 1466 students in grades 5 and 6, and one of their parents, were invited. First, parents' survey packages including information letters, consent forms and self-administered questionnaires were distributed to the children at school with instructions to take them home to be completed by one of their parents (the parent most involved in home food issues) within $3 \mathrm{~d}$. Next, after 
receiving written consent from the parents, child questionnaires were distributed and completed by the students at school. The study was approved by the Norwegian Social Sciences Data Services.

We received 963 completed parent questionnaires (66\%). Response rate ranged from 20 to $100 \%$ among participating classes. Of the 963 parent respondents, $85 \%$ were mothers. The average age of the parents was $39 \cdot 8$ years, and $91 \%$ of the sample was of Norwegian or other Nordic origin. Out of 865 students having written consent from their parents to participate in the study, 796 (92\%) completed the child questionnaire. Of the 796 child respondents, $51 \%$ were girls. Average age was $10 \cdot 8$ (SD 0.6) years.

\section{Measures}

Both parent and child questionnaires were pre-tested for clarity and length among parents $(n 6)$ and children $(n 8)$ not taking part in the study.

\section{Parent questionnaire}

The parent questionnaire included an adapted, validated, Norwegian version of Musher-Eizenman and Holub's ${ }^{(23)}$ CFPQ. The process of translation, adaptation and validation of the CFPQ is described in detail elsewhere ${ }^{(24)}$.

\section{Child questionnaire}

The items constituting the child questionnaire have previously been validated and widely used among Norwegian 6th graders ${ }^{(7,25-30)}$.

The child questionnaire consisted of two parts; one part assessing child cognitions related to $\mathrm{F} \& \mathrm{~V}$ intake, the other assessing child consumption of F\&V. The cognitions part was adapted from the Pro Children study ${ }^{(27)}$ and included variables based on the ASE model. Attitudes were measured with two items for fruit and vegetables respectively ('To eat fruit/vegetables every day gives me more energy' and 'To eat fruit/vegetables every day makes me feel good'). Social influence, which in the present study was limited to parental influence, was measured by four items. Two of these items reflected parental descriptive norms or modelling ('My mother/father eats fruit/vegetables every day') and two items reflected active parental encouragement ('My mother/father encourages me to eat fruit/vegetables every day'). Self-efficacy was measured with two items ('It's easy for me to eat fruit/vegetables every day' and 'If I decide to eat fruit/vegetables every day, I can do it'), and intention with one item ('I want to eat fruit/vegetables every day'). All items had five response categories ( $1=$ 'fully disagree', $2=$ 'partly disagree', $3=$ 'neither agree nor disagree', $4=$ 'partly agree', $5=$ 'fully agree').

Pre-testing of the cognitions part of the questionnaire led to some small adjustments compared with the original items formulated by De Bourdeaudhuij et al. ${ }^{(27)}$. First, the wording of one of the self-efficacy items was changed from negative ('It's difficult for me to eat fruit/vegetables every day') to positive ('It's easy for me to eat fruit/ vegetables every day'), as the children perceived positive wording as more natural. Furthermore, we reversed the response categories from descending numbers $(5=$ 'fully disagree' to $1=$ 'fully agree') to ascending numbers ( $1=$ 'fully disagree' to $5=$ 'fully agree'), as it seems more logical that increasing agreement with statements and increasing numbers accompany each other.

Child consumption of F\&V was assessed using frequency questions adapted from the work of Andersen et $a l^{(25)}$. The present study included four questions about the consumption of F\&V: 'How often do you eat vegetables for dinner', ' $\ldots$ other vegetables', '.... apple, orange, pear and banana' and '... other fruit and berries'. All questions had ten response categories ('never' $=1$, 'less than once a week' $=2$, 'once a week' $=3$, 'twice a week' $=4, \ldots$, 'six times a week' $=8$, 'every day' $=9$, 'several times every day' $=10$ ), which were re-coded to reflect consumption in times per week $(0,0 \cdot 5,1,2, \ldots, 6$, $7,10)$ as suggested by Bere et al. ${ }^{(28)}$.

\section{Data analyses}

The SPSS statistical software package version 18 (SPSS Inc., Chicago, IL, USA) was used for the data analyses. First, the proportion of children reporting daily F\&V consumption (i.e. seven times or more per week) was calculated. This was done by: (i) making sum-scores of the re-coded fruit and vegetable items, respectively; (ii) dichotomizing the sumscores as $0=$ not eating fruit/vegetables every day (scores 0 through 6) and $1=$ daily consumption of fruit/vegetables (scores 7 and above); and (iii) running frequencies to find the proportion of children reporting daily fruit and vegetable consumption, respectively. Next, the distribution of scores on each scaling variable was assessed by calculating mean, standard deviation, skewness and kurtosis values. As suggested by Kline ${ }^{(31)}$, we chose to apply cut-off values of $3 \cdot 0$ and 8.0 for skewness and kurtosis, respectively. Cronbach's $\alpha$ coefficients were computed to measure internal consistency of the scales. Bivariate correlation analyses were run between all variables to test for multicollinearity between independent variables and to get a first impression of relationships between independent and dependent variables. As suggested by Haerens and co-workers ${ }^{(32)}$, we applied a cut-off value of $0 \cdot 80$ or greater for multicollinearity.

To examine the contribution of parental feeding practices in explaining the variance in child intentions and behaviours regarding $\mathrm{F} \& \mathrm{~V}$ consumption, taking into account the effects of child cognitions, hierarchical regression analyses were conducted with child intentions to eat F\&V and child self-reported F\&V consumption as dependent variables. Thus, child cognitions were entered into the first block and parental feeding practices were entered into the second block for fruit and vegetable intentions and consumption, respectively.

Since fruit consumption and vegetable consumption can be seen as different behaviours, influenced by different factors ${ }^{(33)}$, analyses were run separately for these 
behaviours. We chose a rather puritan approach to our data, and list-wise deletion was applied for all model analyses. Thus, only dyads with complete data sets for each of the four models tested were included in these analyses (regression on child intention to eat fruit/child fruit consumption: $n 643 / n 628$, regression on child intention to eat vegetables/child vegetable consumption: $n$ 658/n 622). Independent-samples $t$ tests were conducted to test for differences between dyads included in model analyses and those not included due to incomplete data.

\section{Results}

\section{Daily fruit and vegetable consumption}

Daily fruit consumption was reported by $72 \%$ and daily vegetable consumption by $58 \%$ of the children.

\section{Distribution of scores}

Mean scores, standard deviations and Cronbach's $\alpha$ for F\&V consumption and child cognitions regarding F\&V consumption are presented in Tables 1 and 2 for fruit and vegetables, respectively. Means, standard deviations and $\alpha$ coefficients for parental feeding practices are presented in Table 3. Screening for skewness and kurtosis showed that all child and parent variables had values well within the range of chosen cut-offs (skewness: $-2 \cdot 24$ to $1 \cdot 81$, kurtosis: $-0 \cdot 80$ to $5 \cdot 46$ ). Cronbach's $\alpha$ ranged from $0 \cdot 44$ to $0 \cdot 84$.

\section{Correlations between variables}

No multicollinearities were found between the independent variables. Bivariate correlations between independent and dependent variables are presented in Table 4. All ASEbased variables showed moderate to high correlations with both child intention to eat F\&V and child F\&V consumption. Only a few CFPQ-based variables correlated (weakly) with child intentions and behaviour regarding fruit consumption, while several CFPQ-based variables correlated (weakly) with child intentions and behaviour regarding vegetable consumption.

\section{Regression analyses}

Intention to eat fruit and fruit consumption

Hierarchical regression analyses on child intention to eat fruit every day revealed that child cognitions accounted

Table 1 Mean, SD and Cronbach's $\alpha$ for child fruit consumption and ASE-based variables regarding fruit consumption: grade 5 and 6 students $(n 796)$ from eighteen schools in south-west Norway

\begin{tabular}{lccc}
\hline Variable/scale (number of items) & Mean & SD & $\alpha$ \\
\hline Fruit consumption (2) & 6.39 & 2.17 & 0.67 \\
Attitudes, fruit (2) & 4.15 & 0.87 & 0.63 \\
Social (parental) influence, fruit (4) & 3.47 & 0.99 & 0.79 \\
Self-efficacy, fruit (2) & 4.55 & 0.74 & 0.59 \\
Intention, fruit (1) & 4.25 & 1.07 & - \\
\hline
\end{tabular}

ASE, Attitude-Social Influence-Self-Efficacy model. for $29 \%$ of the variance explained. Including parental feeding practices in the model added another 3\% to the variance explained (Table 5). All ASE-based variables were positively related to child intention to eat fruit (in order of importance): self-efficacy $(\beta=0 \cdot 28, P<0 \cdot 001)$, attitude $(\beta=0.25, \quad P<0.001)$ and parental influence $(\beta=0 \cdot 18, \quad P<0 \cdot 001)$. Expanding the ASE model by adding parental feeding practices revealed that the variable child control was negatively related to child intention to eat fruit $(\beta=-0 \cdot 14, P<0 \cdot 001)$.

Hierarchical regression analyses on child self-reported fruit consumption revealed that child cognitions (including intention) accounted for $25 \%$ of the variance. The following ASE-based variables were positively related to fruit consumption (in order of importance): intention $(\beta=0 \cdot 23, P<0 \cdot 001)$, self-efficacy $(\beta=0 \cdot 22, P<0 \cdot 001)$ and parental influence $(\beta=0 \cdot 14, P<0 \cdot 001)$. Inclusion of parental feeding practices in the model did not contribute significantly to explaining the variance in child fruit consumption (Table 6).

\section{Intention to eat vegetables and vegetable consumption} Hierarchical regression analyses on child intention to eat vegetables every day revealed that child cognitions accounted for $42 \%$ of the variance. All ASE-based variables were positively related to child intention to eat vegetables (the order of importance was the same as for

Table 2 Mean, SD and Cronbach's $\alpha$ for child vegetable consumption and ASE-based variables regarding vegetable consumption: grade 5 and 6 students $(n 796)$ from eighteen schools in south-west Norway

\begin{tabular}{lccc}
\hline Variable/scale (number of items) & Mean & SD & $\alpha$ \\
\hline Vegetable consumption (2) & 5.48 & 2.22 & 0.50 \\
Attitudes, vegetables (2) & 3.67 & 1.07 & 0.78 \\
Social (parental) influence, vegetables (4) & 3.55 & 1.01 & 0.82 \\
Self-efficacy, vegetables (2) & 3.99 & 1.06 & 0.73 \\
Intention, vegetables (1) & 3.56 & 1.29 & - \\
\hline
\end{tabular}

ASE, Attitude-Social Influence-Self-Efficacy model.

Table 3 Mean, SD and Cronbach's $\alpha$ for parental feeding practices (CFPQ-based variables): parents ( $n$ 963) of grade 5 and 6 students from eighteen schools in south-west Norway

\begin{tabular}{lccc}
\hline Variable/scale (number of items) & Mean & SD & $\alpha$ \\
\hline Monitoring (4) & 4.05 & 0.56 & 0.84 \\
Child control (5) & 2.38 & 0.58 & 0.55 \\
Encourage balance and variety (4) & 4.47 & 0.51 & 0.66 \\
Environment (4) & 3.92 & 0.68 & 0.57 \\
Involvement (3) & 3.46 & 0.83 & 0.67 \\
Pressure to eat (3) & 2.77 & 0.97 & 0.61 \\
Restriction for weight (8) & 2.20 & 0.80 & 0.83 \\
Food as reward (2) & 1.56 & 0.79 & 0.69 \\
Restriction for health (4) & 2.88 & 1.00 & 0.73 \\
Teaching nutrition (3) & 4.13 & 0.66 & 0.44 \\
Modelling (4) & 3.86 & 0.74 & 0.66 \\
Emotion regulation (1) & 1.47 & 0.75 & - \\
\hline
\end{tabular}

CFPQ, Comprehensive Feeding Practices Questionnaire. 
Table 4 Pearson's correlation between independent and dependent variables: parents $(n 963)$ and grade 5 and 6 students ( $n$ 796) from eighteen schools in south-west Norway

\begin{tabular}{|c|c|c|c|c|}
\hline Independent variable & $\begin{array}{c}\text { Intention to } \\
\text { eat fruit }\end{array}$ & $\begin{array}{c}\text { Fruit } \\
\text { consumption }\end{array}$ & $\begin{array}{l}\text { Intention to eat } \\
\text { vegetables }\end{array}$ & $\begin{array}{c}\text { Vegetable } \\
\text { consumption }\end{array}$ \\
\hline \multicolumn{5}{|l|}{ Child cognitions (ASE-based) } \\
\hline Attitude & $0 \cdot 41^{\star \star \star}$ & $0 \cdot 31^{\star \star \star}$ & $0.51^{\star \star \star}$ & $0 \cdot 34^{\star \star \star}$ \\
\hline Social (parental) influence & $0 \cdot 36^{\star \star \star}$ & $0 \cdot 35^{\star \star \star}$ & $0 \cdot 43^{\star \star \star}$ & $0 \cdot 36^{\star \star *}$ \\
\hline Self-efficacy & $0 \cdot 46^{\star \star \star}$ & $0 \cdot 41^{\star \star \star}$ & $0.58^{\star \star \star}$ & $0 \cdot 47^{\star \star *}$ \\
\hline Intention & $1 \cdot 00$ & $0 \cdot 41^{\star \star \star}$ & $1 \cdot 00$ & $0 \cdot 41^{\star \star \star}$ \\
\hline \multicolumn{5}{|c|}{ Parental feeding practices (CFPQ-based) } \\
\hline Monitoring & 0.02 & 0.03 & -0.00 & $0.08^{*}$ \\
\hline Child control & $-0 \cdot 12^{\star \star}$ & -0.06 & $-0.08^{*}$ & $-0 \cdot 15^{\star \star \star}$ \\
\hline Encourage balance and variety & 0.02 & $0 \cdot 08^{*}$ & $0 \cdot 08^{*}$ & $0 \cdot 18^{\star \star \star}$ \\
\hline Environment & 0.02 & $0 \cdot 10^{\star \star}$ & 0.05 & $0 \cdot 20^{\star \star \star}$ \\
\hline Involvement & 0.01 & 0.04 & 0.06 & $0 \cdot 10^{*}$ \\
\hline Pressure to eat & -0.04 & -0.03 & $-0.09^{\star}$ & $-0.09^{\star}$ \\
\hline Restriction for weight & -0.03 & 0.05 & -0.00 & -0.02 \\
\hline Food as reward & -0.07 & -0.04 & $-0.07^{\star}$ & $-0.09^{\star}$ \\
\hline Restriction for health & -0.05 & -0.04 & $-0.09^{\star}$ & $-0 \cdot 12^{\star \star}$ \\
\hline Teaching nutrition & 0.06 & $0.09^{*}$ & $0 \cdot 07^{*}$ & $0 \cdot 15^{\star \star \star}$ \\
\hline Modelling & 0.06 & $-0 \cdot 11^{\star \star}$ & 0.05 & $0 \cdot 09^{*}$ \\
\hline Emotion regulation & $-0 \cdot 08^{*}$ & -0.02 & -0.04 & -0.03 \\
\hline
\end{tabular}

ASE, Attitude-Social Influence-Self-Efficacy model; CFPQ, Comprehensive Feeding Practices Questionnaire. ${ }^{\star} P<0.05,{ }^{\star \star} P<0.01,{ }^{\star \star \star} P<0.001$.

Table 5 Hierarchical regression analyses on child intention to eat fruit every day: grade 5 and 6 students and their parents ( 643 dyads) from eighteen schools in south-west Norway

\begin{tabular}{lcc}
\hline Independent variable & Block $1 \beta$ & Block $2 \beta$ \\
\hline Child cognitions (ASE-based) & & \\
Attitude & $0 \cdot 25^{\star \star \star}$ & $0 \cdot 26^{\star \star *}$ \\
Social (parental) influence & $0 \cdot 18^{\star \star \star}$ & $0 \cdot 17^{\star \star \star}$ \\
Self-efficacy & $0 \cdot 28^{\star \star \star}$ & $0 \cdot 28^{\star \star \star}$ \\
Parental feeding practices (CFPQ-based) & & -0.02 \\
Monitoring & & $-0 \cdot 14^{\star \star *}$ \\
Child control & & -0.06 \\
Encourage balance and variety & -0.07 \\
Environment & & -0.00 \\
Involvement & & -0.02 \\
Pressure to eat & & -0.07 \\
Restriction for weight & & -0.04 \\
Food as reward & & -0.04 \\
Restriction for health & & -0.03 \\
Teaching nutrition & 0.29 & 0.32 \\
Modelling & & $0.03^{\star}$ \\
Emotion regulation & & \\
$R^{2}$ (explained variance) &
\end{tabular}

ASE, Attitude-Social Influence-Self-Efficacy model; CFPQ, Comprehensive Feeding Practices Questionnaire.

${ }^{*} P<0.05,{ }^{* \star \star} P<0.001$.

child intention to eat fruit): self-efficacy $(\beta=0 \cdot 37$, $P<0.001)$, attitude $(\beta=0.25, P<0 \cdot 001)$ and parental influence $(\beta=0 \cdot 19, P<0 \cdot 001)$. Adding parental feeding practices to the model did not increase the variance explained (Table 7).

Regarding child self-reported vegetable consumption, hierarchical regression analyses revealed that child cognitions (including intention) accounted for $27 \%$ of the variance explained, and inclusion of parental feeding
Table 6 Hierarchial regression analyses on child fruit consumption: grade 5 and 6 students and their parents ( 628 dyads) from eighteen schools in south-west Norway

\begin{tabular}{llr}
\hline Independent variable & Block $1 \beta$ & Block $2 \beta$ \\
\hline Child cognitions (ASE-based) & & \\
Attitude & 0.07 & 0.08 \\
Social (parental) influence & $0 \cdot 14^{\star \star \star}$ & $0 \cdot 13^{\star \star}$ \\
Self-efficacy & $0 \cdot 22^{\star \star \star}$ & $0 \cdot 22^{\star \star \star}$ \\
Intention & $0 \cdot 23^{\star \star \star}$ & $0.24^{\star \star \star}$ \\
Parental feeding practices (CFPQ-based) & & -0.01 \\
Monitoring & & 0.02 \\
Child control & & 0.00 \\
Encourage balance and variety & & 0.06 \\
Environment & & -0.01 \\
Involvement & & 0.02 \\
Pressure to eat & & 0.04 \\
Restriction for weight & & -0.00 \\
Food as reward & & 0.04 \\
Restriction for health & & 0.04 \\
Teaching nutrition & 0.04 \\
Modelling & 0.25 & 0.26 \\
Emotion regulation & & 0.01 \\
$R^{2}$ (explained variance) & & \\
$R^{2}$ change & & \\
\hline
\end{tabular}

ASE, Attitude-Social Influence-Self-Efficacy model; CFPQ, Comprehensive Feeding Practices Questionnaire.

${ }^{\star *} P<0.01,{ }^{\star \star \star} P<0.001$.

practices accounted for an additional $4 \%$ (Table 8 ). The following variables within the ASE model were positively related to child vegetable consumption (in order of importance): self-efficacy $(\beta=0 \cdot 27, P<0 \cdot 001)$, parental influence $(\beta=0 \cdot 16, P<0 \cdot 001)$ and intention $(\beta=0 \cdot 15$, $P<0 \cdot 001)$. Adding parental feeding practices to the model revealed that only the environment variable $(\beta=0 \cdot 10$, $P<0 \cdot 01)$ was significantly, and positively, related to child vegetable consumption. 
Table 7 Hierarchical regression analyses on child intention to eat vegetables every day: grade 5 and 6 students and their parents (658 dyads) from eighteen schools in south-west Norway

\begin{tabular}{lcr}
\hline Independent variable & Block $1 \beta$ & Block $2 \beta$ \\
\hline Child cognitions (ASE-based) & & \\
Attitude & $0 \cdot 25^{\star \star \star}$ & $0 \cdot 24^{\star \star \star}$ \\
Social (parental) influence & $0 \cdot 19^{\star \star \star}$ & $0 \cdot 19^{\star \star \star}$ \\
Self-efficacy & $0 \cdot 37^{\star \star \star}$ & $0 \cdot 37^{\star \star \star}$ \\
Parental feeding practices (CFPQ-based) & & -0.01 \\
Monitoring & & -0.03 \\
Child control & & -0.03 \\
Encourage balance and variety & -0.05 \\
Environment & -0.02 \\
Involvement & -0.03 \\
Pressure to eat & & 0.04 \\
Restriction for weight & & -0.01 \\
Food as reward & & -0.03 \\
Restriction for health & & 0.01 \\
Teaching nutrition & & -0.01 \\
Modelling & 0.42 & 0.42 \\
Emotion regulation & & 0.01 \\
$R^{2}$ (explained variance) & & \\
$R^{2}$ change & & \\
\hline
\end{tabular}

ASE, Attitude-Social Influence-Self-Efficacy model; CFPQ, Comprehensive Feeding Practices Questionnaire.

${ }^{* * *} P<0.001$

Table 8 Hierarchial regression analyses on child vegetable consumption: grade 5 and 6 students and their parents (622 dyads) from eighteen schools in south-west Norway

\begin{tabular}{|c|c|c|}
\hline Independent variable & Block $1 \beta$ & Block $2 \beta$ \\
\hline \multicolumn{3}{|l|}{ Child cognitions (ASE-based) } \\
\hline Attitude & 0.08 & $0.08^{*}$ \\
\hline Social (parental) influence & $0 \cdot 16^{* * *}$ & $0 \cdot 14^{\star *}$ \\
\hline Self-efficacy & $0 \cdot 27^{\star \star \star}$ & $0 \cdot 24^{\star \star \star}$ \\
\hline Intention & $0 \cdot 15^{\star \star}$ & $0 \cdot 15^{\star \star}$ \\
\hline \multicolumn{3}{|c|}{ Parental feeding practices (CFPQ-based) } \\
\hline Monitoring & & -0.00 \\
\hline Child control & & -0.06 \\
\hline Encourage balance and variety & & 0.08 \\
\hline Environment & & $0 \cdot 10^{\star \star}$ \\
\hline Involvement & & 0.01 \\
\hline Pressure to eat & & -0.02 \\
\hline Restriction for weight & & 0.01 \\
\hline Food as reward & & 0.00 \\
\hline Restriction for health & & -0.07 \\
\hline Teaching nutrition & & 0.02 \\
\hline Modelling & & 0.00 \\
\hline Emotion regulation & & 0.06 \\
\hline $\begin{array}{l}R^{2} \text { (explained variance) } \\
R^{2} \text { change }\end{array}$ & 0.27 & $\begin{array}{l}0 \cdot 31 \\
0 \cdot 04^{\star *}\end{array}$ \\
\hline
\end{tabular}

ASE, Attitude-Social Influence-Self-Efficacy model; CFPQ, Comprehensive Feeding Practices Questionnaire.

${ }^{\star} P<0.05,{ }^{\star \star} P<0.01,{ }^{\star \star \star} P<0.001$.

\section{Differences between dyads included and dyads not included}

Independent-samples $t$ tests were conducted to compare variable scores (model variables and sociodemographic variables) for dyads included in model analyses and those not included due to incomplete data. Of the twenty-six variables tested, we found only two variables with significantly different scores for dyads included and dyads not included. These variables were (child-reported) self-efficacy regarding fruit consumption $($ mean $=4 \cdot 58, \mathrm{sD} 0 \cdot 70$ for dyads included and mean $=4 \cdot 37$, SD $0 \cdot 91$ for dyads not included, $t(142)=2 \cdot 32, P=0 \cdot 02)$ and (parent-reported) child control (mean $=2 \cdot 41, \mathrm{SD} 0.57$ for dyads included and mean $=2 \cdot 29$, SD 0.59 for dyads not included, $t(725)=1.93, P=0 \cdot 05)$. The magnitude of the differences in means (mean difference $=$ $0 \cdot 21$ for self-efficacy and mean difference $=0 \cdot 12$ for child control) was very small $\left(\eta^{2}=0.007\right.$ for self-efficacy and $\eta^{2}=0.005$ for child control). Thus, these results suggested that the differences between dyads included and dyads not included in our model analyses were negligible.

\section{Discussion}

The aim of the present study was to explore the roles of child cognitions and parent-reported feeding practices in explaining the variance in child intentions and behaviour regarding F\&V consumption. Our results showed that both child cognitions and (some) parent-reported feeding practices were associated with child intentions and behaviour regarding F\&V consumption. However, child cognitions played a greater role than parent-reported feeding practices in explaining the variance in both child intentions and behaviour.

Regression analyses showed that a large portion of the variance in child intention to eat fruit and in child fruit consumption (29\% and 25\%, respectively) could be explained by child cognitions as postulated by the ASE model. This also applied to intention to eat vegetables and to consumption of vegetables ( $42 \%$ and $27 \%$, respectively). Thus, our results support the use of the ASE model for this purpose. Among the ASE-based variables measured in our study, self-efficacy appeared as the single most important variable in explaining intentions and behaviour regarding F\&V consumption. According to the ASE model, self-efficacy can be expected to have a direct effect on behaviour as opposed to other cognitions such as attitudes and perceived social influence, which effects seem to be mediated through intentions ${ }^{(17,34)}$. However, previous research is inconsistent about the relationship between self-efficacy and F\&V consumption ${ }^{(29,35-40)}$. This may be due to different operationalizations of the selfefficacy construct ${ }^{(7)}$. For example, positive $v$. negative wording of the self-efficacy items might have an impact on the results. The self-efficacy measure in the present study was derived from the Pro Children project ${ }^{(27)}$. However, we changed the wording of one of the original self-efficacy items from negative to positive, leading to an increase of the internal consistency of the measure compared with studies using an unrevised version of the Pro Children self-efficacy measure ${ }^{(27,41)}$. The $\alpha$ coefficients in the present study were 0.59 and 0.73 for self-efficacy regarding fruit and vegetables, respectively. The studies by De Bourdeaudhuij et al. ${ }^{(27)}$ and Sandvik et al. ${ }^{(41)}$ both had $\alpha$ levels below $0.50(0 \cdot 39-0 \cdot 49)$ for self-efficacy 
regarding F\&V consumption. Revision of the Pro Children self-efficacy measure was encouraged by Sandvik and coworkers $^{(41)}$, and in a later study the measure was revised by simply removing the negatively worded item. Still, no direct relationship from self-efficacy to child F\&V consumption was found ${ }^{(29)}$. Revision of the self-efficacy measure in the present study (by changing the wording from negative to positive) resulted not only in an increased internal consistency; it also resulted in a large direct effect of self-efficacy on F\&V consumption as postulated by the ASE model. Thus, it seems like the wording and composition of measures may have great impact on the results.

Parental influence (as perceived by the children) also appeared as a significant correlate of both intentions and behaviour regarding F\&V consumption. In a study by De Bourdeaudhuij et al $^{(7)}$ both parental modelling and active parental encouragement (as perceived by the children) were found to be associated with daily consumption of F\&V. Several previous studies also reported (perceived) parental modelling as a correlate of child F\&V consumption $^{(25,39,42-44)}$. Attitudes, however, were strong correlates of intentions to eat $\mathrm{F} \& \mathrm{~V}$, but seemed to have no relationship to $\mathrm{F} \& \mathrm{~V}$ consumption in our sample. This is in line with previous research, which found only weak associations between attitudes and F\&V consumption ${ }^{(7,38)}$. Strong associations between attitudes and intention and weak associations between attitudes and consumption could be expected, as intention is theorized to mediate the relationship between attitudes and behaviour ${ }^{(16,17)}$.

Expanding our ASE-based model by including parents' reports of their feeding practices indicated that some parental feeding practices do have an influence on child intentions and behaviour regarding $\mathrm{F} \& \mathrm{~V}$ consumption: the variable child control was negatively associated with child intention to eat fruit, and the variable environment was positively associated with child vegetable consumption. However, the portion of variance explained by these feeding practices was rather small. There are many possible explanations for this. First of all, there might be a gap between the parents' report on their own behaviour and their children's perception of it. This is supported by our finding of a highly significant positive association between parental influence (parental modelling and active parental encouragement), as perceived by the children, and child intentions and behaviour regarding F\&V consumption. However, it is also possible that the child reports were more highly related to the outcomes of interest because of mono-method bias. Alternatively, the weak associations between parent-reported feeding practices and the dependent variables compared with the strong associations between child cognitions and the same dependent variables may be caused by a difference in specificity of the independent variables. That is, the parent-reported feeding practices measure (CFPQ) assesses general constructs of (un)healthy eating, while the items for the child-reported social cognitions are specific to
F\&V consumption. Another possible explanation for our findings might be that parental feeding practices are internalized within the child through a socialization process, which in turn is expressed via child cognitions.

As far as we know, only one previous study ${ }^{(22)}$ has used a combination of a cognitive model and a pure feeding practices measure to assess the role of child cognitions and parental influence (as reported by parents) on child healthy eating intentions and behaviour. That study by Hewitt and Stephens ${ }^{(22)}$ was very similar to ours, as it examined the roles of child cognitions measured by Ajzen's ${ }^{(16)}$ TPB and parental feeding practices measured by Birch et al.'s ${ }^{(8)}$ CFQ in predicting healthy eating intentions and behaviour among 10-13-year-old New Zealand children. Thus, it seems worthwhile to compare these studies. An objective in both studies was to test if an expansion of the social cognition model, by including parents' reports on feeding practices, could increase the variance explained for child healthy eating intentions and behaviour. Both studies supported the application of cognitive models for this purpose. However, the inclusion of parent-reported feeding practices did not increase the explanatory power of the social cognition model in Hewitt and Stephens ${ }^{\text {(22) }}$ study. They concluded that the role of parental feeding practices in terms of control and restriction seemed to have no relationship to the children's reported intentions and behaviours regarding healthy eating, and they suggested that the role of parental influence should be further examined. The present study can be considered an answer to their suggestion, as we included a broader spectrum of parental feeding practices in our model (not only controlling and restrictive practices).

\section{Strengths and limitations}

Among the strengths of the present study is that we have reports from two different sources: parents and children. Thus the 'common methods problem' regarding parental feeding practices (reported by parents) and child intention and behaviour regarding F\&V consumption (reported by children) is reduced. However, this might also be a limitation, referring back to the above mentioned possible gap between parental reports and child perceptions. Another strength of the present study is its large sample size, which allows the application of rather sophisticated statistical analyses and increases the statistical power of the results.

One obvious limitation of the study is its cross-sectional design, which does not allow for causal inferences. Another limitation is the application of a self-report FFQ for the assessment of child F\&V consumption. According to a review conducted by McPherson et al. ${ }^{(45)}, 24 \mathrm{~h}$ recalls and food records seem to work better among school-aged children than FFQ. Frequency questions asking about usual intake require abstract thinking, as well as basic reading and arithmetic skills, which may be too advanced 
for young children. Furthermore, children may have difficulties recalling past events ${ }^{(46)}$. Andersen et al. ${ }^{(25)}$ found that FFQ tended to overestimate the intake of F\&V compared with $7 \mathrm{~d}$ food records. This was also observed by Baranowski et al. ${ }^{(47)}$ and van Assema et al. ${ }^{(48)}$. On the other hand, Andersen et $a l^{(25)}$ found that the energy intake based on food records was underestimated by about $20 \%$.

The presence of some low $\alpha$ coefficients might also be a limitation, as low internal consistencies may obscure the relationship between variables ${ }^{(49)}$. In particular, the low values for $\alpha$ found in some of the CFPQ scales may be questioned. Some low $\alpha$ values were also found by Musher-Eizenman \& Holub ${ }^{(23)}$ and Musher-Eizenman et $a l^{(50)}$. However, it is important to note that all CFPQ subscales have few items. According to Cortina ${ }^{(51)}$, it is well known that the number of items has an effect on $\alpha$, especially at low levels of average item inter-correlation. That is, if a scale has enough items (e.g. more than twenty), it can have an $\alpha$ of $\geq 0.70$ even when the correlations among items are very small ${ }^{(51)}$. Thus, lower values of $\alpha$ can be expected from shorter scales like the subscales of the CFPQ. Developing survey instruments always involves a trade-off between internal consistency (using multiple items) and practicality. The CFPQ is an instrument aiming to tap many different aspects of feeding practices. Using only a few items in each subscale makes it less tiresome, and therefore more applicable. However, one may question if the brief subscales of the CFPQ sufficiently capture the different aspects of feeding practices.

\section{Conclusions and implications}

In the present study, child cognitions explained a large portion of child intentions and behaviour regarding F\&V consumption. However, a few parent-reported feeding practices also contributed, although to a small extent, to the explained variance in child intentions to eat fruit and in child consumption of vegetables. We suggest that future research on this topic address possible mediating effects of child cognitions on the relationships between parent-reported feeding practices and child healthy eating intention and behaviour. Extended knowledge about the pathways of these variables is warranted to inform future parent-child intervention programmes. Additional suggestions include the development and application of: (i) a more extensive measure of perceived parental feeding practices among children, to close the possible gap between parents' reports of their feeding practices and children's perceptions of them; and (ii) food-specific measures of parental feeding practices. Moreover, the findings of the present study need to be replicated with more valid and reliable measures of fruit and vegetable consumption.

\section{Acknowledgements}

This study was funded by the University of Stavanger. No conflicts of interest exist. E.L.M. designed the study, collected and analysed the data, and drafted the manuscript. N.C. $\varnothing$. and T. $\varnothing$. supervised the study and contributed to the analyses and writing of the article. All of the authors read and approved the final manuscript. The authors thank participating schools, students and parents. Moreover, they thank Renaa Matbaren and Kino1 for their generous donation of a free restaurant meal and free movie tickets for a lottery among participants.

\section{References}

1. Øverby NC \& Andersen LF (2002) Ungkost-2000: Nationwide Dietary Survey among 4th and 8th Graders in Norway. Oslo: National Nutrition Council.

2. Yngve A, Wolf A, Poortvliet E et al. (2005) Fruit and vegetable intake in a sample of 11-year-old-children in 9 European countries: The Pro Children cross-sectional survey. Ann Nutr Metab 49, 236-245.

3. Birch LL (1990) Development of food acceptance patterns. Dev Psychol 26, 515-519.

4. Lien N, Lytle L \& Klepp K (2001) Stability in consumption of fruit, vegetables and sugary foods in a cohort from age 14 to age 21. Prev Med 33, 217-226.

5. Mikkilä V, Rasanen L, Raitakari O et al. (2004) Longitudinal changes in diet from childhood into adulthood with respect to risk of cardiovascular diseases: The Young Finns Study. Eur J Clin Nutr 58, 1038-1045.

6. Hanson NI, Neumark-Sztainer D, Eisenberg ME et al. (2005) Associations between parental report of the food home environment and adolescent intakes of fruits, vegetables and dairy foods. Public Health Nutr 8, 77-85.

7. De Bourdeaudhuij I, Te Velde SJ, Brug J et al. (2008) Personal, social and environmental predictors of daily fruit and vegetable intake in 11-year-old children in nine European countries. Eur J Clin Nutr 62, 834-841.

8. Birch LL \& Davidson KK (2001) Family environmental factors influencing the developing behavioural controls of food intake and childhood overweight. Pediatr Clin North Am 48, 893-907.

9. Birch LL, Fisher JO, Grimm-Thomas K et al. (2001) Confirmatory factor analyses of the Child Feeding Questionnaire: a measure of parental attitudes, beliefs and practices about child feeding and obesity proneness. Appetite 36, 201-210.

10. Faith MS, Scanlon KS, Birch LL et al. (2004) Parent-child feeding strategies and their relationships to child eating and weight status. Obes Res 12, 1711-1722.

11. Birch LL \& Fisher JO (2000) Mothers' child feeding practices influence daughters' eating and weight. Am J Clin Nutr $\mathbf{7 1}$, 1054-1061.

12. Hendy HM \& Raudenbush B (2000) Effectiveness of teacher modeling to encourage food acceptance in preschool children. Appetite 34, 61-76.

13. Lee Y \& Birch LL (2002) Diet quality, nutrient intake, weight status and feeding environments of girls meeting or exceeding the American Academy of Pediatrics recommendations for total dietary fat. Minerva Pediatr 54, 179-186.

14. Wardle J, Cooke L, Gibson L et al. (2003) Increasing children's acceptance of vegetables; a randomized trial of parent-led exposure. Appetite 40, 155-162.

15. Blanchette L \& Brug J (2005) Determinants of fruit and vegetable consumption among 6-12-year-old children and 
effective interventions to increase consumption. J Hum Nutr Diet 18, 431-443.

16. Ajzen I (1991) The theory of planned behaviour. Organ Behav Hum Decis Process 50, 179-211.

17. Kok G, Schaalma H, De Vries H et al. (1996) Social psychology and health education. In European Review of Social Psychology, pp. 241-282 [W Stroebe and M Hewstone, editors]. New York: John Wiley \& Sons Ltd.

18. De Bruijn G-J, Kremers SPJ, Schaalma H et al. (2005) Determinants of adolescent bicycle use for transportation and snacking behaviour. Prev Med 40, 658-667.

19. Conner M \& Abraham C (2001) Conscientiousness and the theory of planned behaviour: toward a more complete model of the antecedents of intention and behaviour. Perc Soc Psychol Bull 27, 1547-1561.

20. Courneya KS, Bobick TM \& Schinke RJ (1999) Does the theory of planned behaviour mediate the relation between personality and exercise behaviour: adding the activity trait to the theory of planned behaviour. Basic Appl Soc Psychol 21, 317-324.

21. De Bruijn G-J, Kremers SP, de Vries H et al. (2007) Associations of social-environmental and individual-level factors with adolescents soft drink consumption: results from the SMILE study. Health Educ Res 22, 227-237.

22. Hewitt AM \& Stephens C (2007) Healthy eating among 10-13-year-old New Zealand children: understanding choice using the Theory of Planned Behaviour and the role of parental influence. Psychol Health Med 12, 526-535.

23. Musher-Eizenman DR \& Holub SC (2007) Comprehensive Feeding Practices Questionnaire: validation of a new measure of parental feeding practices. J Pediatr Psychol 32, 960-972.

24. Melbye EL, Øgaard T \& Øverby NC (2011) Validation of the comprehensive feeding practices questionnaire with parents of 10-to-12-year-olds. BMC Med Res Methodol 11, 113.

25. Andersen LF, Bere E, Kolbjørnsen N et al. (2004) Validity and reproducibility of self-reported intake of fruit and vegetables among 6th graders. Eur J Clin Nutr 58, 771-777.

26. Bere E \& Klepp K-I (2004) Correlates of fruit and vegetable intake among Norwegian schoolchildren: parental and self reports. Public Health Nutr 7, 991-998.

27. De Bourdeaudhuij I, Klepp K-I, Due P et al. (2005) Reliability and validity of a questionnaire to measure personal, social and environmental correlates of fruit and vegetable intake in 10-11-year-old children in five European countries. Public Health Nutr 8, 189-200.

28. Bere E, Veierød MB \& Klepp KI (2005) The Norwegian School Fruit Programme: evaluating paid vs. no-cost subscriptions. Prev Med 41, 463-470.

29. Sandvik C, Gjestad R, Brug J et al. (2007) The application of a social cognition model in explaining fruit intake in Austrian, Norwegian and Spanish schoolchildren using structural equation modelling. Int J Behav Nutr Phys Act 4, 57.

30. Sandvik C, Gjerstad R, Samdal O et al. (2010) Does socioeconomic status moderate the associations between psychosocial predictors and fruit intake in schoolchildren? The Pro Children study. Health Educ Res 25, 121-134.

31. Kline RB (2005) Principles and Practice of Structural Equation Modeling, 2nd ed., pp. 48-51. New York: Guilford Press.

32. Haerens L, Craeynest M, Deforche B et al. (2008) The contribution of psychosocial and home environmental factors in explaining eating behaviours in adolescents. Eur J Clin Nutr 62, 51-59.
33. Reinaerts E, De Nooijer J, Candel M et al. (2007) Explaining school children's fruit and vegetable consumption: the contribution of availability, accessibility, exposure, parental consumption and habit in addition to psychosocial factors. Appetite 48, 248-258.

34. Ajzen I (2002) Perceived behavioural control, self-efficacy, locus of control, and the theory of planned behaviour. J Appl Soc Psychol 32, 665-683.

35. Domel SB, Thompson WO, Davis HC et al. (1996) Psychosocial predictors of fruit and vegetable consumption among elementary school children. Health Educ Res 11, 299-308.

36. Resnicow K, Davis-Hearn M, Smith M et al. (1997) Socialcognitive predictors of fruit and vegetable intake in children. Health Psychol 16, 272-276.

37. Reynolds KD, Hinton AW, Shewchuk R et al. (1999) Social cognitive model of fruit and vegetable consumption in elementary school children. J Nutr Educ 31, 23-30.

38. Lien N, Lytle L \& Komro KA (2002) Applying theory of planned behaviour to fruit and vegetable consumption of young adolescents. Am J Health Promot 16, 189-197.

39. Young EM, Fors SW \& Hayes DM (2004) Associations between perceived parent behaviours and middle school student fruit and vegetable consumption. J Nutr Educ Behav 36, 2-8.

40. Martens MK, Van Assema P \& Brug J (2005) Why do adolescents eat what they eat? Public Health Nutr 8, $1258-1265$.

41. Sandvik C, De Bourdeadhuij I, Due P et al. (2005) Personal and environmental factors regarding fruit and vegetable intake among schoolchildren in nine European countries. Ann Nutr Metab 49, 255-266.

42. Cullen KW, Baranowski T, Rittenberry L et al. (2001) Childreported family and peer influences on fruit, juice and vegetable consumption: reliability and validity of measures. Health Educ Res 16, 187-200.

43. Wind M, De Bourdeadhuij I, Te Velde SJ et al. (2006) Correlates of fruit and vegetable consumption among 11-year-old Belgian-Flemish and Dutch schoolchildren. J Nutr Educ Behav 38, 211-221.

44. Rasmussen M, Krølner R, Klepp K-I et al. (2006) Determinants of fruit and vegetable consumption among children and adolescents: a review of the literature. Part 1: Quantitative studies. Int J Behav Nutr Phys Act 3, 22.

45. McPherson RS, Hoelscher DM, Alexander M et al. (2000) Dietary assessment methods among school-aged children: validity and reliability. Prev Med 31, 11-33.

46. Randall E (1991) Measuring food use in school-aged children. J Sch Health 61, 201-203.

47. Baranowski T, Smith L, Baranowski J et al. (1997) Low validity of a seven-item fruit and vegetable food frequency questionnaire among third-grade students. J Am Diet Assoc 97, 66-68.

48. Van Assema P, Brug J, Ronda G et al. (2002) A short Dutch questionnaire to measure fruit and vegetable intake: relative validity among adults and adolescents. Nutr Health 16, 85-106.

49. Cullen KW, Baranowski T, Owens E et al. (2003) Availability, accessibility and preferences for fruit, $100 \%$ fruit juice and vegetables influence children's dietary behaviour. Health Educ Behav 30, 615-626.

50. Musher-Eizenman DR, de Lauzon-Guillain B, Holub SC et al. (2009) Child and parent characteristics related to parental feeding practices. A cross-cultural examination in the US and France. Appetite 52, 89-95.

51. Cortina JM (1993) What is coefficient alpha? An examination of theory and applications. $J$ Appl Psychol 78, 98-104. 